\title{
Study on the European framework for the application of the active ageing index
}

\author{
Gianina Chirugu $^{1}$, and Felicia Andrioni ${ }^{* 2}$ \\ ${ }^{1}$ University of Craiova, Faculty of Social Sciences, 13 A. I. Cuza Street, Craiova, Romania \\ ${ }^{2}$ University of Petroșani, Department of Socio-Human Sciences, 20 University Street, Petroşani, \\ Romania
}

\begin{abstract}
The challenges associated with the ageing population are important and continuous growth across the world, especially in Europe, the continent with the oldest population. The fundamental objective of active ageing interventions is to optimise opportunities for health, participation and security so as to increase the quality of life of the population with ageing. The Active Ageing Index is a flexible comparative analysis tool that has the mission to help promote and implement active ageing. Thus, the purpose of this paper is to analyse the phenomenon of active ageing from the perspective of the active ageing index in the European area. The methodology used consisted of document analysis, study for several countries in the European space such as: Italy, Germany, Poland, Spain, Romania, analysis and comparison of statistic data. The results obtained show that the role of this active ageing index is to capture the various facets of active ageing, measuring the contribution of older people (women and men) to economic and social life and to the extent to which the environment in which they live stimulates them in this regard to provide more active participation in employment, social life and to lead independent lives.
\end{abstract}

\section{Introduction}

The phrase "grow old and stay active" was adopted by the World Health Organization in the late 1990s and was originally intended to convey a more complete message that "ageing healthily" includes, besides care and health, additional factors. which influences the way the individual and the population age. Active ageing aims to eliminate age-based discrimination and raise awareness of the diversity of needs of older people and is a constant process to optimize opportunities for staying healthy, participatory and safe in order to increase the quality of life during ageing, enabling the elderly to maintain a good mental, social and mental potential throughout their lives and get involved in society according to their needs, desires and abilities, elderly people constitute the largest social group that needs the family and community protection $[1,2]$. It is a necessity that older people involved themselves or take part in the active decisions referring to their lives [3]. Corman (2005) considered that all the stakeholders will work together on the social map in

${ }^{*}$ Corresponding author: felicia_andrioni@yahoo.com 
the configuration of integrated, individualized, personalized elements that involve active ageing [4].

The theories that support active ageing are the theory of activity and the theory of continuity. As regards the theory of activity, it is considered that a well-adapted elderly person is one who remains active for as long as possible, involved in social life, which will give that person satisfaction and increased self-esteem; however, it should not be overlooked that this type of behaviour is satisfying when it is congruent with the previous lifestyle; a lifelong passive person may wish, without being adversely affected, to continue his or her previous lifestyle [5]. According to the theory of continuity, senior citizens replace lost roles with similar ones, continuing to maintain typical ways of adapting to the environment, thus ensuring their inner balance, tend to engage in similar activities and continue their family lifestyle. as until retirement.

\section{Generalities on the ageing phenomenon throughout Europe}

Population ageing is a global phenomenon, being particularly present in Europe and according to the United Nations data the proportion of the elderly population will increase in the long run. It is known that in Europe the concept of "active ageing" appeared much later, in 1999, in European Union documents. From this perspective, retirement was seen as a coercive decision. Throughout life, the risk of marginalization and possible exclusion of the elderly from the labour market will continue to increase. After all, older employees often find that early retirement is the only choice they have. Thus, policies have been introduced (in the sector of employment in the labour market and social security systems, on the company and society level) in order to encourage long-term employment and delayed retirement [6]. The most discussed in the European framework were the policies in the field of employment on the labour market and in the social security systems. In this regard, increasing the employment rate for the elderly has been the subject of several working groups and summits around the theme of "active ageing" [7]. Ageing often comes with many changes, psychological, medical, and social. The interventions that can be carried out to increase the well-being of this particular category of people can be multiple. The social assistance services available to these persons are present on several levels, and the reduction of the pressure that most often falls on the shoulders of the family can be achieved on these levels [8].

In order to reinforce the positive stereotypes of old age and the elderly, one should promote and apply social dialogue based on community programs with a balanced vision of the population different age groups and with a deeper awareness about the differences in experience throughout life.

\section{The Active Ageing Index in Europe}

Active ageing [9] means ageing in optimal health, playing an active role in society and proving professional fulfilment, but also autonomy in daily life and involvement in civic activities. Active ageing includes both the individual process and the social opportunities of health, participation and integration structures. The fundamental objective of interventions in the field of active ageing is to optimize opportunities for health, participation and security so as to increase the quality of life of the population along with ageing. On October $12^{\text {th }} 2012$, at a meeting organized by the European Center for Social Assistance and Research Policies in Vienna (ECV), in close collaboration with the European Commission, the Directorate-General for Employment, Social Affairs and Inclusion and the Commission The United Nations Economic Strategy for Europe has developed the Active Ageing Index 
(AAI) which is a new analytical tool that aims to help policy makers in developing policies for active and healthy ageing. Its purpose is to indicate the untapped potential of older people and to offer a more active participation in employment, in social life and to lead an independent life. Mobilizing potential for both older women and men is crucial to ensuring the prosperity of all generations in an ageing society [10]. The index is a flexible benchmarking tool that can be applied at national, regional and local level and aims to help promote and implement active ageing. It captures the various facets of active ageing, measuring the contribution of older people (women and men) to economic and social life and the degree to which the environment in which they live stimulates them. The active ageing index contains 22 indicators grouped in 4 categories: a) employment, social participation; b) independent, healthy and safe living, c) capacity and living environment that encourages active ageing. The selection and specification of indicators contributes to a stronger effort by all Member States to promote active ageing, taking into account solidarity between generations, capturing the multidimensional aspects of ageing, which makes it possible to formulate policy recommendations for those countries in comparative data base in different fields including active ageing [11].

A broader view of the Index is presented in Figure 1 [12] and as can be seen, the first three domains refer to real experiences of active ageing, while the fourth domain captures the active ageing capacity, determined by the individual, the characteristics and environmental factors.

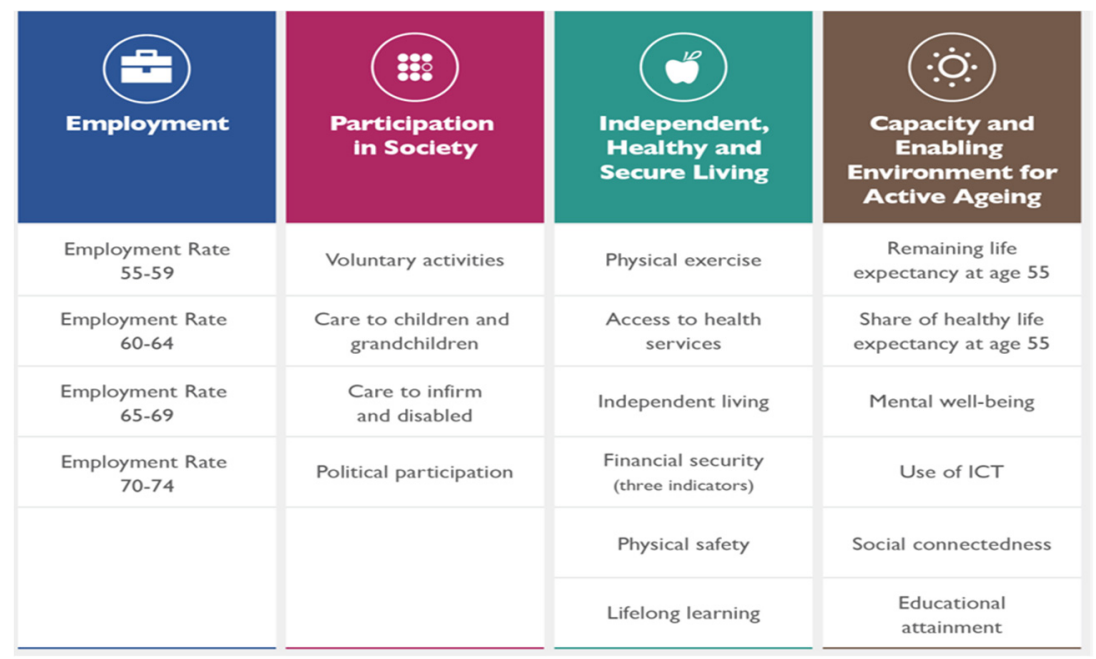

Fig. 1. Active Ageing Index [12].

The aims of the areas include encouraging the prolongation of working life and maintaining working capacity, promoting participation in the socio-economic, cultural, political life, including non-discrimination and social inclusion of the elderly, protecting the dignity, health and independence of the elderly, maintaining and increasing solidarity between generations. AAI allows the development of international, national, regional or local comparative analyzes on the active or passive way in which the population ages, these studies can stimulate various countries to exchange experiences on the policies and programs adopted, on the one hand, and on the other another part can contribute to learning from the experiences - both positive and negative of other states. Such an index will fuel better responses geared to active ageing experiences within each state, as well as inform strategic plans at the federal level. The index provides a picture of the ageing big picture in Europe and is therefore a tool for informing decision-making not only at national but also 
regional level, while providing abundant opportunities for reflection on the evidence collected - for collaboration, exchange of good practices and implementation of new policies.

On the European level, Figure 2 shows both the values for each area of the active ageing index and the overall value of the AAI for 2020, which varies between 28.4-47.8, with Sweden having the best score and Greece is the lowest, and Romania ranked 26th, followed by Croatia.

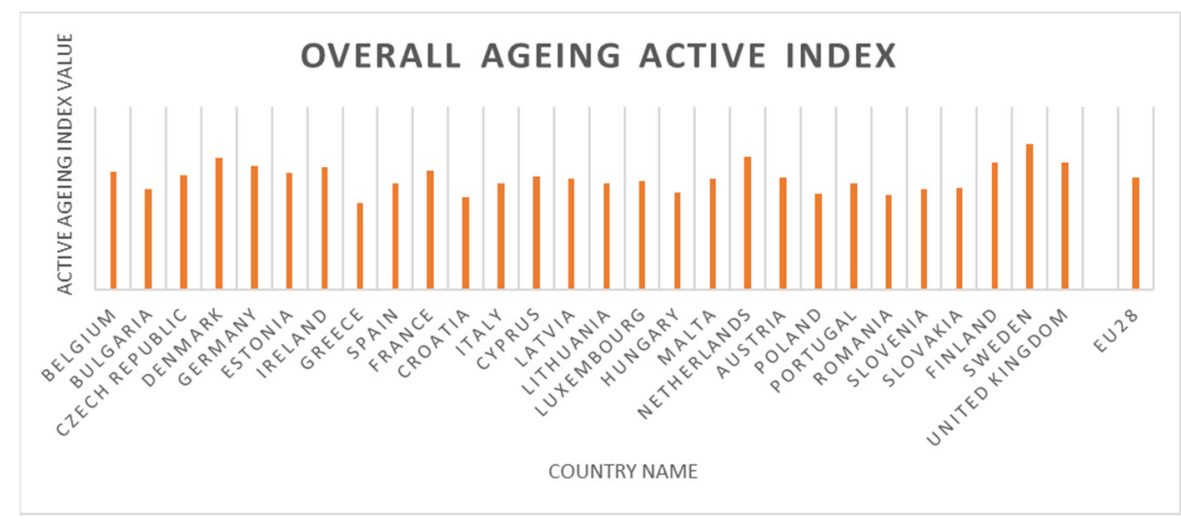

Fig. 2. Overall Active Ageing Index [12].

\section{The methodological approach}

The general purpose of the paper aimed at analysing the phenomenon of active ageing from the perspective of the active ageing index in the European space. The universe of research targeted the population of five European countries: Italy, Germany, Poland, Spain, and Romania. The methodology used was quantitative, but also qualitative based on the following methods such as: document analysis, comparative analysis of the indicators included in the four fields of analysis, statistical data analysis. The phenomenon studied on the level of the investigated population, as well as the analysis and comparison of the most current statistical data (2020) confers an element of novelty on the active ageing of the population. The research questions used were: 1) What is the active ageing index in the countries covered by this research? 2) What are the similarities and differentiations of active ageing in relation to the four areas of AI in Italy, Germany, Poland, Spain, and Romania? The analysis of documents as the first method used in the preliminary investigation phase aimed at the analysis of specialized studies and official reports with reference to the active ageing index: the reports made by the European Commission: Inequality in active ageing: Evidence from a new individual-level index for European countries. Ageing and Society (Barslund et all, 2019), Strategies of Active Ageing in Europe: Making an Asset of Longevity (Walker \& Zaidi, 2019), Active ageing: a strategic policy solution to demographic ageing in the European Union (Walker \& Maltby, 2012). The analysis of the mentioned documents aimed at understanding the topicality of the topic in the real world. The second method used, the comparative analysis, was based on statistical data analysed and interpreted regarding the four specific analytical dimensions of the active ageing index, dimensions that allowed the comparison of statistical data for each country. In the comparative analysis the tool used was the Active ageing index proposed by the European Commission which contains 22 indicators grouped into 4 categories: a) employment; b) social participation; c) independent, healthy and safe living, d) capacity and living environment that encourages active ageing. Depending on the four categories 
mentioned, the indicators were measured separately for men and women, and the values range from 0 to 100 (100 being maximum).

This method was significant in obtaining relevant information on the values of the country-specific indicators for each country in the group of five countries selected for this study.

\section{Data analysis and interpretation. The results obtained}

The results show that the role of this active ageing index is to capture the various facets of active ageing, measuring the contribution of older people (women and men) to economic and social life and the degree to which the environment in which they live stimulates them. Figures 3 and 4 graph the values of the active ageing index for each sex in the European context in 2020 .

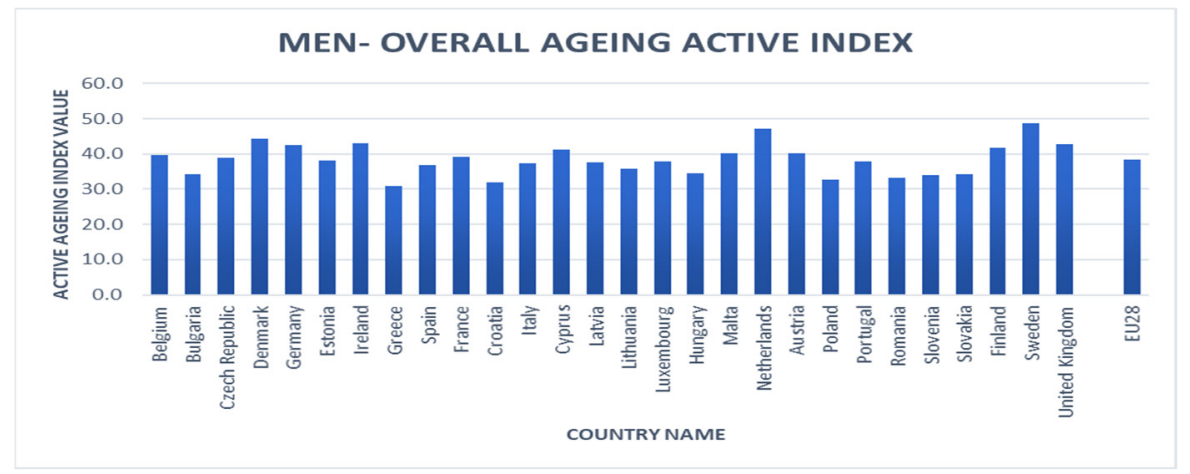

Fig. 3. Men overall Active Ageing Index [12].

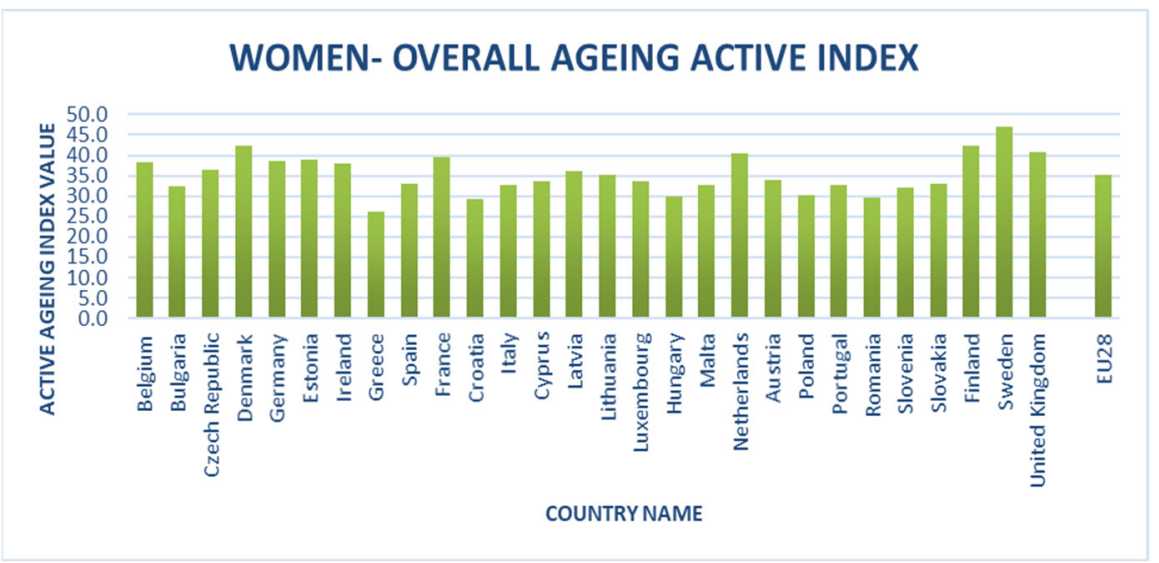

Fig. 4. Women overall Active Ageing Index [12].

\subsection{Analysis of the active ageing index in Italy, Germany, Poland, Spain, Romania}

\subsubsection{Analysis of the active ageing index in Italy}

Using the active ageing index (AAI), specialized studies have described the evolution of active ageing in Italy by measuring four points between 2007 and 2016 for different 
population groups, based on gender, geographical region, educational level, income, family context and the type of locality [13]. The overall score of the AAI in the period 2007-2016 increased, the largest increase was registered in the field of employment largely determined by the pension reform, which increased the retirement age and reduced the chances of early retirement and in the field of active ageing capacity followed by the field of independent living, the score decreased slightly in the field of participation.

Gender policies should consider providing more opportunities for active ageing, especially for older women with low levels of education and low incomes, for those living in less urbanized areas, including rural areas, and for couples without children or for those living as single parents. Often, in the case of IAA areas or individual indicators, scores have decreased in the last decade, especially among older people with a higher level of education and / or income.

The family context affects women's and men's participation in society differently. While women show a high level of social participation when living alone or with a partner and children, men do so when they are single parents or a partner without children.

Thus, interventions to promote social participation according to family typology should be gender-based. Active ageing may be more difficult in rural areas, especially for women. Therefore, political efforts to promote active ageing by type of residential locality should focus mainly on rural contexts.

\subsubsection{Analysis of the active ageing index in Germany}

Over the last decade, Germany has implemented a number of pension, labour market and long-term care reforms, and the idea of active ageing (Aktives Altern in German) has been introduced into policy and societal discussions. In 2008, as in other European countries, Germany was hit by the economic crisis, which led to a downturn in the economy. However, the German workforce was robust and, after a brief rise in the unemployment rate, recovered quickly and the employment rate even began to rise. German decisionmakers have implemented several reforms aimed at expanding, including closing early retirement options, increasing the number of official retirement options, introducing training programs and strengthening professional activities and private pensions. In addition, new retirees in Germany are, on average, better educated and qualified, as well as healthier than their predecessors. It could be argued that in Germany there is a gap in active ageing between privileged and non-privileged older people.

It seems that the policy and development of German society are moving towards active ageing, but not all senior citizens are equally part of this development. The most recent studies on AAI in Germany focused on the differences between social groups and their development between 2008 and 2014. These groups are defined on the basis of three criteria: education, socio-economic status and place of residence. First, formal education is considered to be a determining factor for active ageing [14].

The results show that, although the score of the active ageing index increased from 2008 to 2014, the level of education of older people influences the value of AAI and that the environment in which the elderly person lives (rural or urban) has a limited impact in determining values in Germany, because the differences between groups according to this criterion are small.

\subsubsection{Analysis of the active ageing index in Poland}

The main purpose of the specialized studies was to examine the values of AAI for certain subgroups of population (by gender, place of residence, education and income) in Poland and the way they have changed over time. Increasing the employment rate of the elderly 
population [15], which could be the result of more effective labour market policies, is the key factor behind increasing the values of AAI.

In the general assessment of AAI values, practically no change was observed in rural areas over time, while for urban areas there was an increase. Therefore, the place of life disparity is not only significant, but tends to increase over time. The level of education could also be a reason for the considerable differences in ageing experiences and active ageing outcomes. The most striking differences between these groups could be observed in physical activity and in the use of ICT indicators.

Relevant additional policy reforms are needed to mobilize the potential of the elderly in the country who are at a disadvantage compared to other older people. There is a need for wide and open dissemination (in various ways) of these results to stakeholders and interest groups (the elderly). We hope that the analysis presented will initiate a discussion on the programs, actions and measures needed to reduce the differences in areas between the relevant subpopulations, which are presented in this analysis. Also in Poland, the urban context seems to be offering more opportunities for active ageing [16].

\subsubsection{Analysis of the active ageing index in Spain}

The regional active ageing index (AAI) in Spain was calculated for three time periods 2008, 2012 and 2016. In addition, the analysis of the evolution of the global AAI, scores and indicators specific to the field over time in different regions is presented. To understand gender differences, data are provided for men and women [17]. The study shows that the AAI can be calculated for Spain on the regional level or NUTS-2, using secondary data from national sources based mainly on large statistical operations for the regions with the largest sample sizes. This study refers to the importance of policies at regional level for the results of active ageing.

The increase in scores was observed in all areas except social participation. The calculation of AAI on the regional level is important because policies that have an impact on the dimensions of active ageing are often designed and implemented on the local and regional level. The calculation of the regional AAI can help to analyse current policy influences and develop new policies for active ageing and allow for higher levels of fulfilment of the potential of older men and women.

This can be achieved by using the quantitative evidence-based results that AAI provide to identify areas of challenge and by setting targets to be achieved. If AAI is considered a common tool for monitoring active ageing at regional level, decisions should be taken to obtain good quality data for territorial divisions.

\subsubsection{Analysis of the active ageing index in Romania}

Romania has low scores both in terms of economic development and active ageing index compared to the EU 28 average. The results presented in this study show that Romania follows the same trend in terms of active ageing as the rest of the EU Member States between 2010 and 2016. However, the gap between Romania and the other Member States has widened, EU countries have moved in the same direction, but the average speed has been higher than in Romania.

Regional differences should be taken into account when designing social policies for active ageing. No Romanian region is in the top of the active ageing index, but this can be improved through appropriate policies. The variation from one region to another is uneven, reflecting local peculiarities. The overall score of the independent, healthy and safe living area indicates a large gap between Romania and most EU Member States. 
Romania has the second lowest level in the EU in this field. Poverty is more acute in Romania compared to the EU average, but the gap has narrowed since 2010. At the same time, life expectancy of 50 years at the age of 55 has increased, but the share of healthy life years in life expectancy remaining at the age of 55 registered a slight decrease in the analysed time interval. The indicator that measures the subjective assessment of the mental well-being of seniors has experienced the most heterogeneous evolution across regions.

\subsection{Comparative analysis of the active ageing phenomenon in Italy, Germany, Poland, Spain and Romania}

The comparative analysis was performed along four dimensions of analysis of the phenomenon of active ageing from the perspective of a) employment on the labour market; b) social participation; c) independent living; d) capacity and living environment that encourages active ageing.

Following the comparative analysis of the data provided by each country covered by this study, on the active ageing index in the European space according to Figure 5, it is observed that Germany ranks first in terms of active ageing index, followed by Italy, Spain, Poland and Romania.

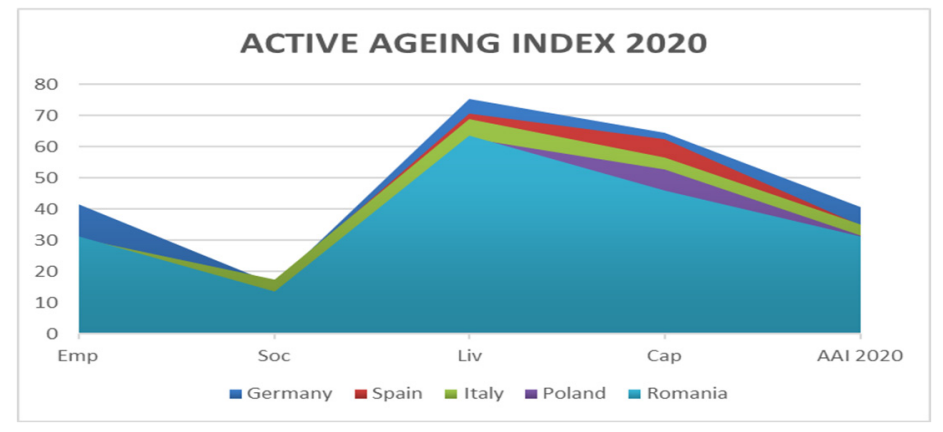

Fig. 5. Active Ageing Index.

If the overall score for each domain is analysed and compared, in terms of the size of the analysis population employment, the most active elderly population is Germany, followed by Romania and Italy, as opposed to Poland and Spain which have a low score on this indicator (Figure 6). From the same figure it can be remarked that in the social participation dimension of analysis Italy is in the foreground, whereas in the dimensions of analysis regarding the independent living and capacity and environment conducive to active ageing Germany has the highest score compared to other countries.

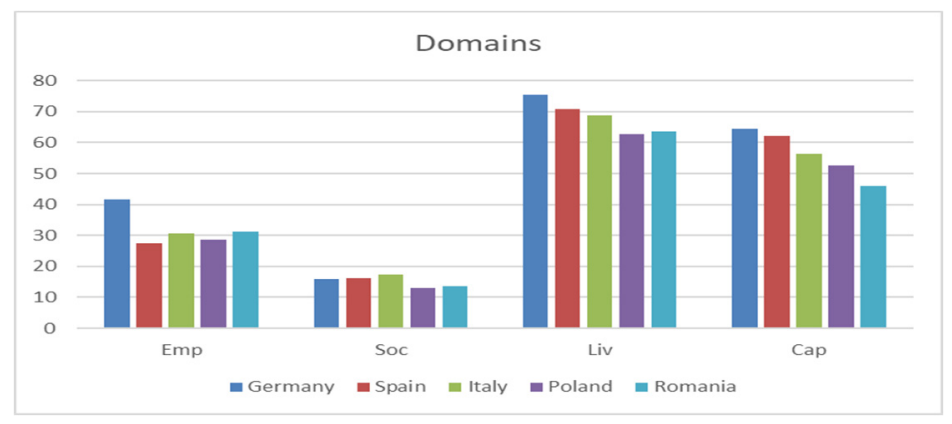

Fig. 6. Domains of Active Ageing Index. 
Analysing the statistical data obtained in 2020 for each indicator of the employment analysis dimension presented in figure 7, Romania ranks first in the occupancy rate of workforce for the age group 70-74 years.

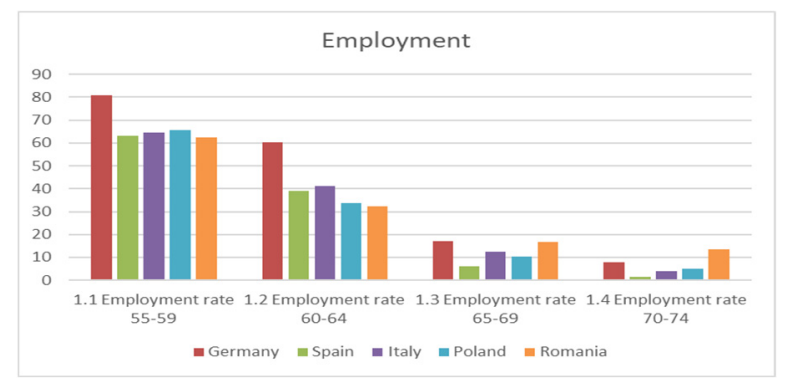

Fig. 7. Indicators of employment.

According to the data obtained for each indicator of the size of the participation analysis presented in Figure 8, in 2020 the elderly in Germany were the most involved in volunteer activities, those in Spain most dedicated to raising children and grandchildren, political life seniors in Germany took care of the most, and the senior generation peers in Italy were the most concerned.

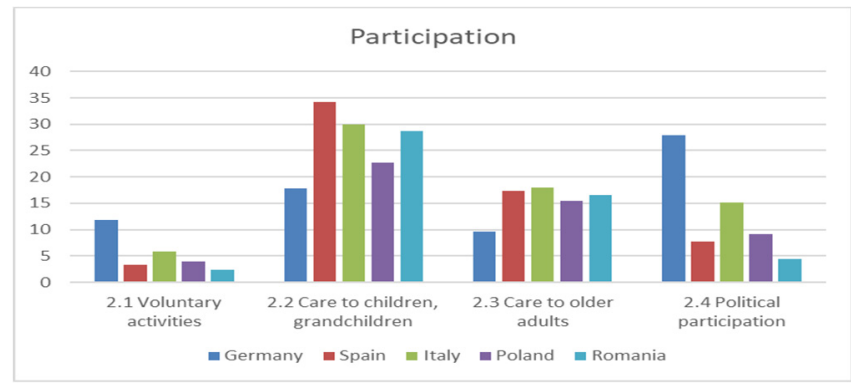

Fig. 8. Indicators of participation.

The independent life of the elderly in Europe is statistically outlined in Figure 9. Spanish seniors spend most of their time studying, the Poles have financial and mental security, and access to health, independent living and exercise come first for the elderly in Germany.

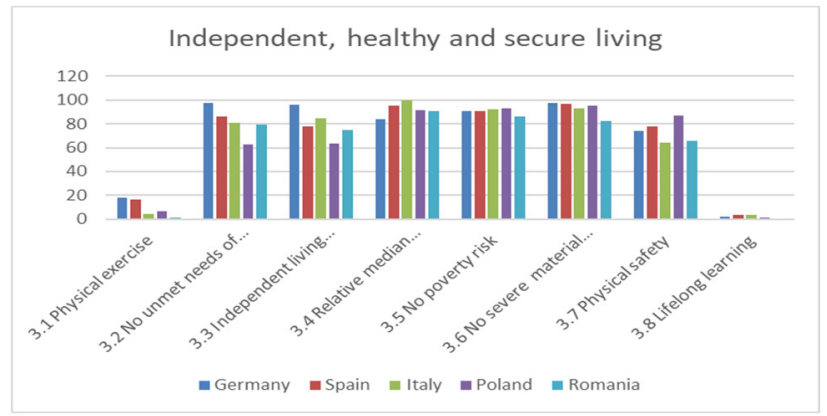

Fig. 9. Indicators of independent life 
Figure 10 illustrates an overview of the environment conducive to active ageing, with Spaniards having the highest life expectancy since age 55 and having the most social contacts, and with the German seniors having very high mental well-being.

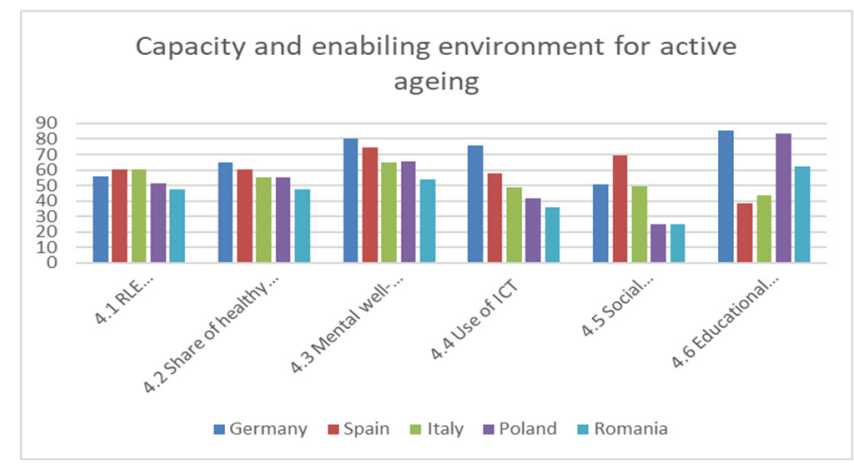

Fig. 10. Indicators of capacity and enabling environment.

\section{Conclusions}

Following the analysis of the active ageing index in the five countries above, it is found that Italy, Germany and Poland have common active ageing characteristics. Lower AAI values are found among people with a lower level of education, women (although genderdisaggregated data were not available for Germany), and people living in rural and semiurban areas, although differences based on the place of residence are not as high as those based on gender and (especially) level of education. The current groups of senior citizens are gradually being replaced by groups with higher levels of education. In this context, AAI levels are likely to increase in the coming decades.

In Romania and Spain, policies and programs in support of the concept of "growing old and staying active" should be improved, the process of active ageing of the individual being a challenge. It is an objective necessity for policies to follow the indicators of health, employability in the labour market, social participation so as to favour the process of active ageing of the population.

Implementing policies and programs that promote active ageing involves taking on personal responsibilities (self-responsibility), adapting the environment to the needs of older people, and intergenerational solidarity. Every person and family must prepare for old age, making personal efforts to adopt a healthy lifestyle throughout life.

The adoption of policies and programs favourable to an active old age is justified from the economic point of view, from the point of view of productivity and of the decrease of the expenses for care.

Although the current trend in some countries is in favour of early retirement, due to social policies that encourage people to retire too early, with the acceleration of the ageing phenomenon, there has already been great pressure to change these policies to keep the elderly who have maintained their health as active as possible. Their activity would help to compensate for the increase in pensions-generated expenses, as well as medical and social costs. 


\section{References}

1. F. Andrioni, Contemporary social work between theory and practice, Academica Greifswald, Germany, (2018)

2. F. Andrioni, Issues regarding the elderly people in the Jiu Valley, in Zenith International Journal of Multidisciplinary Research, 4 (3), 1-7, (2014)

3. S. Corman, A. Pavelescu, Paternalism or active involvement of the elderly in residential care centres, in Scientfic Annuals of Alexandru Ioan Cuza University of Iaşi Sociology and Social Work, XI (1), (2018)

4. S. Corman, About the beneficiaries of social work, in Is Romania different? Society and sociology... where ?, eds. Voicu, B., Rusu, H., Popa, A. E. "Lucian Blaga" University of Sibiu Publishing House, (2005)

5. I. Mâță, Spiritual counseling for the elderly in residential centers (in original in Romanian), The European Institute (2018)

6. G. Chirugu, Theoretical approaches to the ageing phenomenon (in original in Romanian), Craiova, (2021)

7. J. Olivera, Ageing unequally in Europe, in Socio-Economic Review, (2020)

8. J. Amery, About ageing, Revolt and resignation (in original in Romanian), Art Publishing House, Bucharest, (2010)

9. A. Zaidi, Active Ageing Index 2012. Concept, Methodology and Final Results, Vienna, (2013)

10. M. Barslund, M. Von Werder \& A. Zaidi, Inequality in active ageing: Evidence from a new individual-level index for European countries, in Ageing and Society, 39(3), 541-567 (2019) .

11. A. Walker \& A. Zaidi, Strategies of Active Ageing in Europe: Making an Asset of Longevity, (2019)

12. The European Commission, Active Ageing Index project, Available on https://statswiki.unece.org/display/AAI/Active+Ageing+Index+Home

13. A. Principi, M. Tibaldi, L. Quattrociocchi, P. Checcucci, Criteria-specific analysis of the Active Ageing Index (AAI) in Italy (2019)

14. Heß, Moritz \& Naegele, Older Workers' Employment Rate and Active Ageing in Germany, (2018).

15. J. Perek-Bialas, A. Ruzik, L. Vidovicova, Active ageing policies in the Czech Republic and Poland, in International Social Science Journal, Special Issue about Active Ageing, December 2006, No 190, pp. 559-570 ( 2006)

16. M. Leszko, L. Zając-Lamparska, T. Janusz, Ageing in Poland, in The Gerontologist, 55(5), pp. 707-715 (2015)

17. V. Rodriguez-Rodriguez, F. Rojo-Perez, G. Fernandez-Mayoralas, Active Ageing Index: Application to Spanish Regions, Population Ageing 10, pp. 25-40 (2017) 